\title{
Endoscopic removal of a submucosal embedded foreign body in the duodenum
}

Ingested foreign bodies can sometimes become deeply embedded or even cause perforation in the gastrointestinal tract. Retrieval of these foreign bodies by endoscopy can be technically difficult; it may even require surgical exploration. Endoscopic submucosal dissection (ESD) technique-assisted removal of an esophageal foreign body has been reported [1]. We here describe a case of a completely buried foreign body in the duodenum that was successfully removed in a similar fashion.

A 63-year-old lady presented with melena and anemia. Contrast CT showed a 2.4-cm linear hyperdensity at the pylorus without perforation (> Fig.1). During upper endoscopy, a dimple was noted at the first part of the duodenum, with spontaneous pustular discharge and surrounding erythema (> Fig. 2 ). The lady was put under general anesthesia for endoscopic retrieval of the foreign body ( $\vee$ Video 1). First, a mixture of normal saline, epinephrine, and hyaluronic acid was injected submucosally at the suspect opening. A mucosal incision was then created with both insulated-tip and needletype knives (IT Nano and Dual Knife J; Olympus Medical Corporation, Tokyo, Japan) along the site of the opening. After submucosal dissection around the area, a $2.3-\mathrm{cm}$ linear fish bone was found deeply embedded in the submucosa of the first part of the duodenum, with partial penetration through the muscularis propria ( $>$ Fig.3). The fish bone was finally removed with forceps. Endoscopic clips were placed to close the resultant defect $(\vee$ Fig.4). After the procedure, the patient gradually resumed a normal diet and was discharged without any complications.

Surgical exploration of an embedded foreign body in the duodenum is technically challenging, especially in this scenario when the fishbone had not perforated

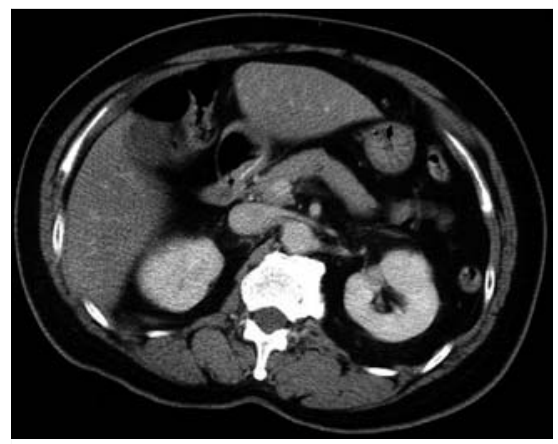

- Fig. 1 CT scan showing a 2.4-cm linear hyperdensity at the pylorus without perforation.

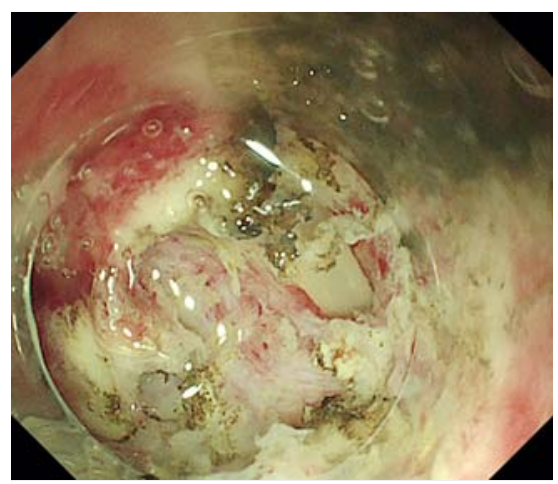

- Fig.3 A fish bone was found deeply embedded in the submucosa of the first part of the duodenum, with partial penetration through the muscularis propria.

the lumen completely. This case demonstrates the feasibility of removing such a foreign body with ESD techniques, avoiding major surgery.

Endoscopy_UCTN_Code_TTT_1AQ_2AH

\section{Competing interests}

The authors declare that they have no conflict of interest.

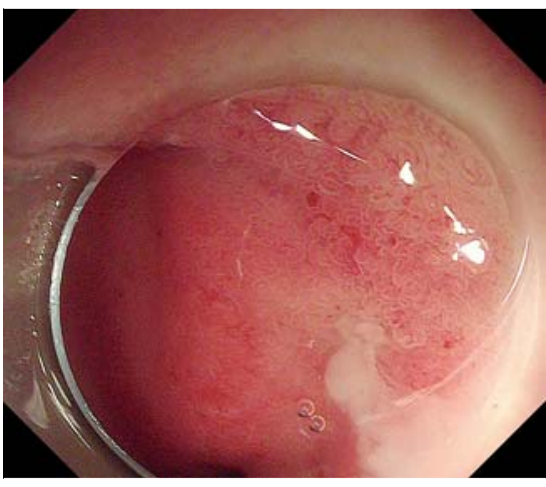

- Fig. 2 A dimple at the first part of duodenum with spontaneous pustular discharge.

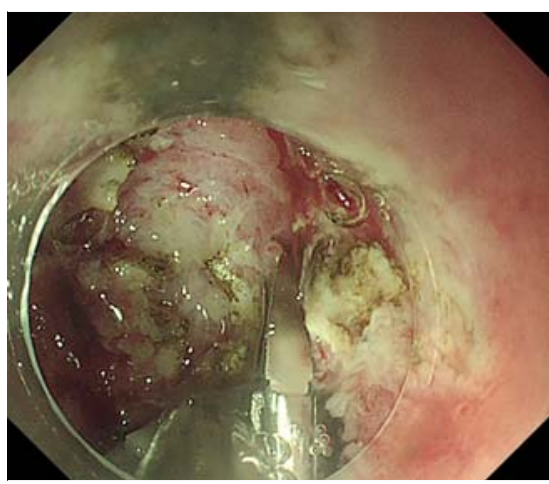

Fig. 4 The defect after endoscopic submucosal dissection was performed.

The authors

Nicole M. Cheng, Hon C. Yip, Shannon M. Chan, Anthony Y. Teoh, Philip W. Chiu, Enders K. Ng

Division of Upper Gastrointestinal and Metabolic Surgery, Department of Surgery, Faculty of Medicine, Prince of Wales Hospital, the Chinese University of Hong Kong 


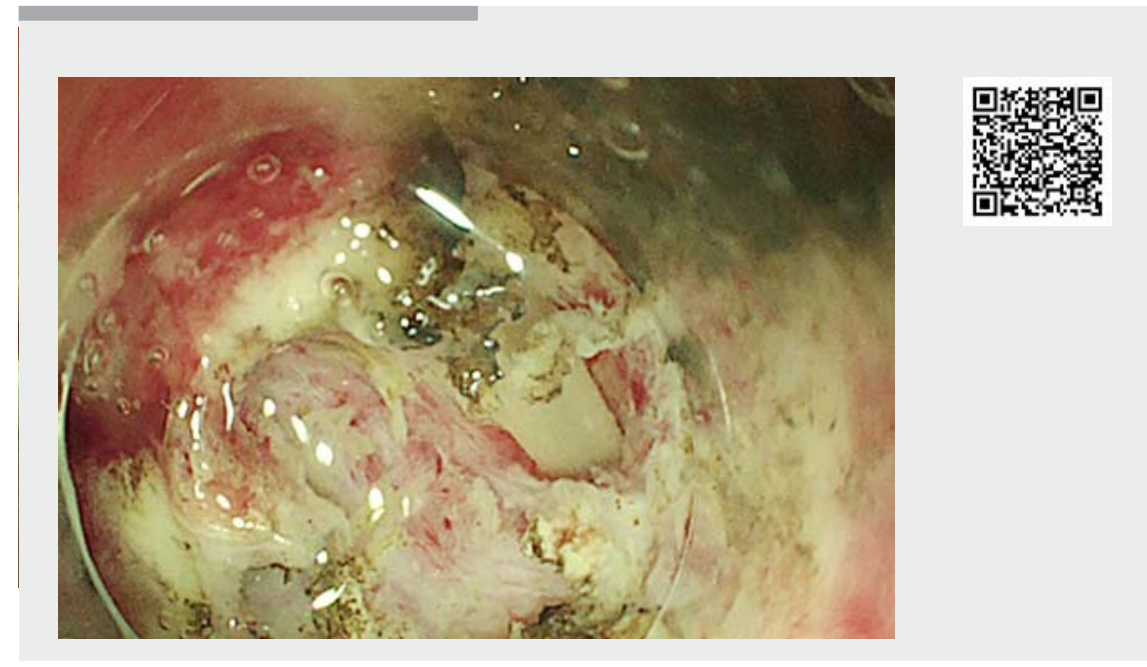

Video 1 Endoscopic removal of a submucosal embedded foreign body in the duodenum.

Corresponding author

\section{Hon Chi Yip, MBChB, FRCSEd (General)}

Department of Surgery, 4/F Lui Che Woo

Clinical Sciences Building, Prince of Wales

Hospital, 30-32 Ngan Shing Street, Shatin,

NT, Hong Kong

Fax: +852-3505-7974

hcyip@surgery.cuhk.edu.hk

\section{Bibliography}

DOI https://doi.org/10.1055/a-1122-8240

Published online: 18.3.2020

Endoscopy 2020; 52: E353-E354

(C) Georg Thieme Verlag KG

Stuttgart · New York

ISSN 0013-726X

\section{ENDOSCOPY E-VIDEOS}

https://eref.thieme.de/e-videos

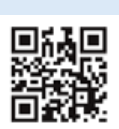

Endoscopy E-Videos is a free access online section, reporting on interesting cases and new techniques in gastroenterological endoscopy. All papers include a high quality video and all contributions are freely accessible online.

This section has its own submission website at https://mc.manuscriptcentral.com/e-videos
[1] Yip HC, Chiu PW, Chan SM et al. Removal of submucosal embedded fish bone in the esophagus with endoscopic submucosal dissection. VideoGIE 2017; 2: 1 